\title{
Comparison Task-Oriented Training according to the Applicable Blocked Practice and Random Practice: Chronic Hemiplegic Patients
}

\author{
Nam-Yung Lee', Suhn-Yeop Kim², Hyun-Seung Song ${ }^{1}$ \\ 'Department of Physical Therapy, The Graduate School, Daejeon University; ${ }^{2}$ Department of Physical Therapy, College of Natural Science, Daejeon \\ University, Daejeon, Korea
}

Purpose: The purpose of this study was to compare the blocked practice and random practice of task-oriented training in patients with chronic stroke to determine the effect of lower extremity muscle activity and balance ability.

Methods: The thirty participants were randomly assigned to either the block practice group (BP) group or the random practice group (RP) and received the training three times per week, 30 minutes per day, for six weeks. Surface electromyography was used for measurement of lower extremity muscle activity. Static balance was to measured the stability index (SI) and weight distribution index (WDI) using the Tetrax. The four square step test (FSST) was used to measure dynamic balance. The paired t-test was used for determination of differences before and after intervention, and the independent t-test was used for determination of differences between groups.

Results: Lower extremity muscle activity, RA and GCM was improved in the RP group after intervention and between groups. TA was significantly improved in the RP group compared with the BP group. In comparison of before and after interventions, SI was

reduced in BP and RP. WDI in OS was reduced in comparison of BP and RP before and after intervention. CS was reduced in BP and RP. The OS and CS was improved in RP compared with BP. In comparison of before and after intervention, FSST was improved in BP and RP. Conclusion: Task-oriented training methods using random practice was found to be effective in promoting lower extremity muscle activity and balance ability in chronic stroke patients.

Keywords: Blocked practice, Random practice, Stroke, Task-oriented training

\section{서 론}

뇌졸중 노인 환자는 마비측 운동기능장애로 선택적인 상하지 조절 능력 감소와 감각장애로 인하여 예측할 수 없는 자세 동요 발생 시 적 절한 조절이 어려워 건강한 노인보다 더 많은 낙상을 경험하게 된다. ${ }^{1}$ 뇌졸중 환자에게 있어 균형유지는 전정계, 시각계, 고유수용성 감각 계, 근골격계 및 인지능력의 상호작용에 의한 복합적 과정으로 자세 를 유지하고 수의적 운동을 하는 동안 자세를 안정시킴으로써 이동 하기나 걷기 등 일상생활동작을 안전하고 독립적으로 수행하는 데 있어 필수항목이다.2

특히 뇌졸중으로 인한 편마비 환자의 경우, 자세 동요가 더 커지고 고유수용성감각(proprioception)의 손상으로 균형능력 저하와 함께 운동 수행 능력이 저하되어 일상생활에 많은 어려움이 생긴다. 뇌졸
중 환자의 균형저하는 주로 고유수용성 감각계의 손상에서 기인하 는 것으로 알려져 있으나, 하지 및 체간근력의 약화도 앉은 자세 및 선자세에서 균형유지를 어렵게 한다. ${ }^{4}$

뇌졸중 환자를 대상으로 운동수행능력 향상을 위한 다양한 중재 방법들이 제시되고 있으나, 단일동작을 반복적으로 훈련하는 방법 보다 기능적 과제로 구성된 활동을 사지 간의 상호작용을 통해 효율 적으로 훈련하는 방식5,6으로 구성된 과제지향적훈련(task-oriented training) 방법이 필요하다. 또한 훈련을 적용하기 전에 대상자의 운 동협응 형태의 질적인 변화에 영향을 미치는 다양한 요인들이 적절 하게 포함되도록 계획해야 한다. 훈련을 계획할 때 훈련 시간과 빈도, 유형, 순서 등을 고려해야 하며, 이때 가장 중요한 요소는 가변성(variability)으로 똑같은 움직임을 반복하지 않도록 해서 학습된 기술이 변화되지 않고 유지되는 것이 중요하다. ${ }^{8}$
Received Jul 23, 2015 Revised Aug 18, 2015

Accepted Aug 20, 2015

Corresponding author Hyun-Seung Song

E-mail songhyunseung@gmail.com
Copylight (C) 2015 The Korea Society of Physical Therapy

This is an Open Access article distribute under the terms of the Creative Commons Attribution Non-commercial License (Http:// creativecommons.org/license/by-nc/3.o.) which permits unrestricted non-commercial use, distribution, and reproduction in any medium, provided the original work is properly cited. 
또한 움직임 기술을 연습할 때 맥락간섭 효과(contextual interference effect)가 발생하는데, ${ }^{9}$ 이는 다양한 요소들 간의 간섭 현상으로 학습이나 기억을 방해하는 것을 뜻한다. ${ }^{10}$

Battig $^{9}$ 그리고 Keetch와 Lee ${ }^{11}$ 는 연습으로 향상된 수행력을 오랫동 안 유지하는 능력인 학습보존(retention)과 학습 경험이 새로운 운동 기술의 수행력과 학습에 영향을 미치는 전이(transfer)에 있어서 맥락 간섭 효과가 높은 상황에서 효과가 더 크다고 하였다. 맥락간섭효과 는 구획 연습(blocked practice)과 무선 연습(random practice)으로 조 절이 가능하며, 이에 대한 효과는 구획연습 상황에서는 낮고 무선 연 습상황에서는 높다. ${ }^{8}$

구획연습은 대상자가 하나의 기술을 학습하는 데 각 변인을 나누 어 일괄적으로 연습하는 것을 의미하고, 무선 연습은 기술의 하위 요 소들을 무작위로 연습하는 것을 뜻한다. Lee ${ }^{12}$ 의 연구에서 학습보존 과 전이가 연령이 높아짐에 따라 무선 연습에서 효과가 더 높다고 하 였다.

과제지향적 훈련과 관련된 연구의 경우 프로그램을 중재기간 동 안 순서대로 진행하는, ${ }^{13}$ 구획연습 방법을 주로 사용하고 있다. 그러 나 낙상은 예측할 수 없는 상황에서 발생하므로 학습보존과 전이 효 과가 높은 무선연습을 통한 운동학습전략이 필요하다.

운동 학습에 있어 무선 연습 방법이 구획 연습 보다 더 효과적이지 만 만성 뇌졸중 환자를 대상으로 실제 차이 비교를 알아본 연구는 부족한 실정이다. 따라서 본 연구 목적은 균형능력 저하로 인해 낙상 의 위험이 높은 만성 뇌졸중 환자를 대상으로 과제지향적 훈련 방법 을 적용 방법에 따라 구획연습과 무선연습의 효과를 비교하고, 하지 근활성도 수준과 균형능력에 미치는 영향을 알아봄으로써 무선연 습 방법의 임상적 유용성을 알아보고자 한다.

\section{연구방법}

\section{1. 연구대상}

본 연구의 대상자는 $\mathrm{G}$ 광역시에 위치한 재활병원에 입원 중인 367명 의 환자 중 연구 참여를 거부한 100 명과 선정 조건에 미달된 144 명, 중 도 퇴원한 20 명, 사망자 3 명, 다른 병원으로 전원 40 명, 건강 악화로 연 구를 계속 진행하지 못한 30 명을 제외한 30 명을 연구대상자로 하였다 모든 대상자는 제비 뽑기를 통해 무작위로 구획연습군(blocked practice group, BP group)과 무선연습군(random practice group, RP group)으 로 각각 15 명씩 배정하였다. 두 군 모두에게 일반 재활훈련으로 중추 신경계발달 재활치료를 1 일 30 분. 주 5 회를 실시하였다. BP군은 일반 재활훈련과 과제지향훈련(task-oriented training, TRT)을 구획연습 방 법으로, RP군은 일반재활훈련과 TRT를 무선연습 방법으로 시행하였 다. 연구 중재는 1 일 30 분, 주 3 회, 총 18 회를 6 주간 실시하였다.
대상자 선정조건은 뇌졸중으로 인해 편마비 진단을 받은 자 중 첫 째, 뇌졸중 진단을 받은 지 6개월이 경과한 자, 둘째, 한국형 간이정신 상태 검사(korea-mini mental state examination) 24점 이상인 자, 셋째, 독립적으로 $10 \mathrm{~m}$ 이상 보행이 가능한 자 넷째, 수정된 경직척도(modified ashworth scale) 2점 이하인 자, 다섯째, 하지에 근골격계 질환이 없는 자로 하였으며 연구 내용에 대한 충분한 설명을 듣고 자발적으 로 동의한 자로 하였다.

\section{2. 실험방법}

\section{1) 하지 근활성도 측정}

하지 근활성도 측정은 표면 근전도(LXM 3208-RF, LAXTHA Inc. Korea)를 사용하였다. 신호의 표본 수집률은 $1,024 \mathrm{~Hz}, 60 \mathrm{~Hz}$ 대역 정지 필터(band stop filter)와 20-500 Hz 대역통과필터(band pass filter)를 사 용하여 잡음을 제거하였다. 수집된 정보의 처리는 Telescanver. 2.92 프 로그램(LAXTHA Inc., Korea)을 사용하였다. 전극을 부착하기 전 피 부저항을 최소화하기 위해 전극 부착 부위의 털을 제거하고 사포로 피부의 각질을 제거한 후 알코올 솜으로 문질러 피부를 청결히 하였 다. 활성전극(active electrode)과 기준전극(reference electrode) 부착은 대퇴직근(rectus femoris, RF), 대퇴이두근(biceps femoris, $\mathrm{BF}$ ), 전경골 근(tibialis anterior, TA), 비복근(gastrocnemius, $\mathrm{GCM}$ )의 근복(muscle belly)에 부착하였다.

각 근육의 부착부위는 먼저 RF는 상전장골극에서 슬개골의 $1 / 2$ 지 점에, $\mathrm{BF}$ 는 좌골결절에서 내측 슬관절의 $1 / 2$ 지점에, $\mathrm{TA}$ 는 슬개골 중 심에서 외측복사뼈까지 거리의 $1 / 2$ 위치에, GCM은 슬와부 중심선에 서 하행 $2 \mathrm{~cm}$ 거리의 외측 표면에 부착하였다..$^{4}$

접지전극(ground electrode)은 측정 시 움직임에 방해가 되지 않는 부위에 부착하였다. 측정한 근전도 신호는 표준화 과정을 거쳐 특정 동작기준 수축값(\%reference voluntary contraction, \%RVC)으로 산출 하여 사용하였다. 기준 수축값 산출은 먼저 제자리에서 안정적으로 선 자세에서 5 초간 준비 후, 5 초 동안 측정하여 전후 1 초를 제외한 3 초의 신호를 사용하였다. 측정은 Tetrax 힘판 위에 선 자세에서 측정 하였다.

\section{2) 균형능력 측정}

정적균형능력 측정은 Tetrax Portable Multiple System (Tetrax Ltd, sunlight, Israel)을 사용하였다. 대상자가 Tetrax 장비 힘판에 양 발을 위치 시키고 바로 선 자세에서 두 가지 방법으로 시행하였다. 첫째, 선 자세 에서 전방을 주시하며 눈을 뜬 상태(open eyes in standing, OS), 둘째, 선 자세에서 전방을 주시하며 눈을 감은 상태(close eyes in standing, $\mathrm{CS})$ 에서 32 초 동안 측정하였다. 4 개의 힘판에 가해지는 수직 압력을 각각의 압력변환기를 통해 $34 \mathrm{~Hz}$ 의 속도로 감지하여 압력의 변동양 
상을 측정하였다. 압력의 변동양상을 통해 안정성지수(stability index, $\mathrm{SI}$ )와 체중분포지수(weight distribution index, WDI)를 구하였다..$^{15}$ 대 상자에게 측정에 대한 충분한 설명 후 3 회 측정하여 평균값을 사용 하였다.

동적균형능력 측정은 Four Square Step 검사(FSST)를 사용하였다. FSST는 십자가 모양의 막대를 바닥에 놓고 4 개의 구역으로 나눈다. 측정 대상자는 정면을 응시한 상태에서 사각형 1 번 구역을 시작으로 하며 $2 \rightarrow 3 \rightarrow 4 \rightarrow 1$ 구역 방향으로 넘고 다시 그 자리에서 $4 \rightarrow 3 \rightarrow 2 \rightarrow 1$ 구역 방 향으로 되돌아오는 시간을 측정하는 검사이다. ${ }^{16}$ 측정은 최초 한번의 연습 후 두 번째 측정값을 사용하였다.

\section{3) 중재방법}

연구 대상자들에 적용한 중재는 Carr와 Shepherd ${ }^{6}$ 가 수정 보완한 과 제지향훈련(task-oriented training)을 사용하였다. TRT 구성은 첫째, 마비측 발을 들고 유지하기, 둘째, 양 발 뒤꿈치를 들고 유지하기, 셋 째, 발판 위로 마비측 다리 올리고 유지하기, 넷째, 발판 위에서 비 마 비측 다리 내리고 유지하기, 다섯째, $2 \mathrm{~m}$ 거리에 있는 의자 반복하여 앉기, 여섯째, 메트로놈에 맞춰 리듬감 있게 $10 \mathrm{~m}$ 걷기로 구성되어 있 다. 모든 훈련은 치료사와 1:1로 진행 되었으며 수행능력 향상에 따라 난이도를 조절하였다. 각 과제를 수행하는 데 소요되는 시간은 약 4 분이며, 과제 수행 후 1 분의 휴식 시간을 주었다. 훈련 도구는 $5-20 \mathrm{~cm}$ 높이의 규격화된 발판세트(Stair set, APSUN, USA), 전동식 테이블 (AP-2010-4, APSUN, USA), 팔걸이가 있는 높이 조절이 가능한 의자, 1 초에 1번씩 소리가 나도록 설정된 전자식 메트로놈(MT-30, MetroTuner, China)을 사용하였다.

\section{3. 자료분석}

본 연구에서 수집된 자료는 Windows용 SPSS Version 17.0 프로그램 (SPSS Inc., Chicago, IL, USA)을 이용하여 통계 처리하였다. 하지 근활 성도와 균형능력의 각 군별중재 전과 후에 평균값 비교를 위하여 대 응 t-검정(paired t-test)을, 군 간 비교는 독립 t-검정(independent t-test) 을 사용하여 분석하였다. 통계적 유의수준은 $\alpha=0.05$ 로 하였다.

\section{결 과}

\section{1. 연구대상자}

본 연구의 $\mathrm{BP}$ 군과 RP군에 참여한 대상자들의 특징은 Table 1과 같으 며, 동질성 검정에서 모든 항목에서 군 간 유의한 차이는 없었다.

\section{2. 하지 근활성도의 차이}

하지 근활성도에서 $\mathrm{RA}$ 의 근활성도는 RP군에서 중재 전후에 유의하 게 향상되었고 $(\mathrm{p}<0.05)$, 군 간 비교에서 RP군이 더 유의하게 향상되 었다 $(\mathrm{p}<0.05)$ (Table 2). BF의 근활성도는 유의한 차이가 없었다. TA의 근활성도는 군 간 비교에서 RP군이 $\mathrm{BP}$ 군보다 유의하게 향상되었다 $(\mathrm{p}<0.05)$ (Table 2). GCM의 근활성도는 RP군이 전후 비교 $(\mathrm{p}<0.01)$ 와 군 간 비교에서 유의한 향상이 있었다 $(\mathrm{p}<0.05)$ (Table 2).

\section{3. 균형능력의 차이}

균형능력에서 SI는 중재 전후 비교에서 $\mathrm{OS}$ 와 $\mathrm{CS}$ 는 $\mathrm{BP}$ 군과 $\mathrm{RP}$ 군 모 두 유의하게 감소하였다 $(\mathrm{p}<0.001)$ (Table 3$)$. 군 간 비교에서 OS에서 $\mathrm{RP}$ 군이 BP군 보다 유의하게 감소하였다 $(\mathrm{p}<0.05)$ (Table 3). WDI는 중 재 전후 비교에서 $\mathrm{OS}$ 는 $\mathrm{BP}$ 군 $(\mathrm{p}<0.05)$ 과 $\mathrm{RP}$ 군 $(\mathrm{p}<0.001)$ 모두 유의하 게 감소하였다(Table 3). CS는 BP군과 RP군 모두 유의하게 감소하였 다 $(\mathrm{p}<0.01)$ (Table 3). 군 간 비교에서는 OS와 CS 모두 RP군이 BP군 보 다 유의하게 감소하였다 $(\mathrm{p}<0.05)$ (Table 3). FSST는 전후 비교에서 BP

Table 1. General characteristics of subjects

\begin{tabular}{lccc}
\hline & BP group $(\mathrm{n}=15)$ & $\mathrm{RP}$ group $(\mathrm{n}=15)$ & $\mathrm{t}$ \\
\hline Sex (Male/Female) & $9 / 6$ & $7 / 8$ & 0.39 \\
Age (year) & $61.8 \pm 12.5^{\mathrm{a}}$ & $60.7 \pm 10.7$ & 0.79 \\
Height $(\mathrm{cm})$ & $163.9 \pm 8.4$ & $162.4 \pm 10.0$ & 0.99 \\
Weight $(\mathrm{kg})$ & $64.4 \pm 8.8$ & $64.3 \pm 8.7$ & 0.39 \\
Etiology & $5 / 10$ & $6 / 9$ & 0.65 \\
$\quad$ Hemmorrhage/lnfaction) & & & \\
Prevalence (months) & $20.6 \pm 11.3$ & $20.6 \pm 11.3$ & 0.97 \\
\hline
\end{tabular}

${ }^{a}$ Mean \pm Standard deviation.

$\mathrm{BP}$, General rehabilitation exercise+blocked practice; RP, General rehabilitation exercise+random practice.

Table 2. Comparison of measured lower extremity muscle activity in BP group and RP group

\begin{tabular}{|c|c|c|c|c|c|c|c|}
\hline & \multicolumn{2}{|c|}{ BP group $(n=15)$} & \multirow{2}{*}{$t^{a}$} & \multicolumn{2}{|c|}{ RP group $(n=15)$} & \multirow{2}{*}{$t^{a}$} & \multirow{2}{*}{$t^{b}$} \\
\hline & Pre-test & Post-test & & Pre-test & Post-test & & \\
\hline $\mathrm{RF}^{\mathrm{d}}(\% \mathrm{RVC})$ & $107.28 \pm 19.42^{c}$ & $108.37 \pm 14.40$ & -0.17 & $111.07 \pm 22.56$ & $127.01 \pm 7.14$ & $-2.46^{\star}$ & $-2.60^{*}$ \\
\hline $\mathrm{BFe}(\% \mathrm{RVC})$ & $103.62 \pm 11.96$ & $104.34 \pm 6.85$ & -0.21 & $104.36 \pm 14.18$ & $109.56 \pm 18.27$ & -1.00 & -0.85 \\
\hline $\mathrm{TA}^{f}(\% \mathrm{RVC})$ & $104.80 \pm 4.26$ & $106.72 \pm 3.62$ & -1.57 & $107.17 \pm 5.18$ & $113.82 \pm 9.73$ & -2.21 & $-2.16^{*}$ \\
\hline $\mathrm{GCM}^{\mathrm{g}}(\% \mathrm{RVC})$ & $99.38 \pm 8.64$ & $102.62 \pm 8.75$ & -1.86 & $102.20 \pm 6.84$ & $111.95 \pm 12.00$ & $-3.76^{+}$ & $-2.23^{*}$ \\
\hline
\end{tabular}

BP, General rehabilitation exercise+blocked practice; RP, General rehabilitation exercise+random practice.

a Within group comparison; 'between group comparison; ' Mean \pm Standard deviation; dRectus femoris; 'Biceps femoris; ${ }^{\mathrm{f} T i b i a l i s ~ a n t e r i o r ; ~}{ }^{9} \mathrm{Gastrocnemius.}$

${ }^{*} p<0.05,{ }^{+} p<0.01$. 
Table 3. Comparison of measured balance in BP group and RP group

\begin{tabular}{|c|c|c|c|c|c|c|c|}
\hline & \multicolumn{2}{|c|}{ BP group $(n=15)$} & \multirow{2}{*}{$t^{a}$} & \multicolumn{2}{|c|}{ RP group $(n=15)$} & \multirow{2}{*}{$t^{a}$} & \multirow{2}{*}{$t^{b}$} \\
\hline & Pre-test & Post-test & & Pre-test & Post-test & & \\
\hline \multicolumn{8}{|c|}{ Stability index } \\
\hline$O S^{d}$ & $32.04 \pm 7.80^{c}$ & $24.05 \pm 2.81$ & $4.75^{+}$ & $34.20 \pm 6.14$ & $21.67 \pm 3.01$ & $7.58^{+}$ & $0.54^{*}$ \\
\hline $\mathrm{CS}^{\mathrm{e}}$ & $32.65 \pm 6.19$ & $24.03 \pm 1.67$ & $5.96^{+}$ & $34.19 \pm 6.35$ & $23.18 \pm 1.48$ & $6.31^{+}$ & 0.34 \\
\hline \multicolumn{8}{|c|}{ Weight distribution index } \\
\hline$O S^{d}$ & $9.30 \pm 3.01$ & $7.69 \pm 1.59$ & $2.59 *$ & $10.21 \pm 3.60$ & $6.19 \pm 1.90$ & $5.54^{+}$ & $2.23^{*}$ \\
\hline $\mathrm{CS}^{\mathrm{e}}$ & $9.28 \pm 3.07$ & $6.84 \pm 1.07$ & $3.43^{+}$ & $9.81 \pm 3.45$ & $5.83 \pm 1.38$ & $4.66^{+}$ & $2.78^{*}$ \\
\hline $\mathrm{FSST}^{\dagger}(\mathrm{sec})$ & $35.01 \pm 14.72$ & $25.87 \pm 10.11$ & $4.09^{+}$ & $33.59 \pm 22.99$ & $20.86 \pm 6.21$ & $2.76^{\star}$ & 1.83 \\
\hline
\end{tabular}

$\mathrm{BP}$, General rehabilitation exercise+blocked practice; RP, General rehabilitation exercise+random practice.

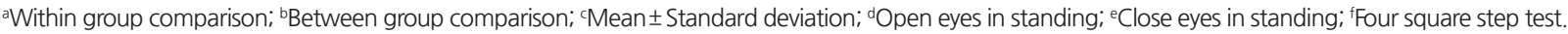
${ }^{*} p<0.05 ;{ }^{*} p<0.01 ;{ }^{*} p<0.001$.

군 $(\mathrm{p}<0.01)$ 과 $\mathrm{RP}$ 군 $(\mathrm{p}<0.05)$ 에서 모두 유의하게 향상되었다(Table 3$)$.

\section{고 찰}

본 연구는 만성 편마비 환자를 대상으로 전이와 파지 효과가 있다고 알려진 무선 연습의 효과를 알아보기 위해 진행하였다. 운동학습에 기초한 과제지향훈련을 $\mathrm{BP}$ 군과 RP군으로 무작위로 배정하여 하지 근활성도와 균형능력에 미치는 영향을 알아보고, 임상에서 균형능력 향상을 위한중재 프로그램의 기초자료로 제공하고자 진행하였다.

Carr와 Shepherd'는 과제지향적 접근방법이 뇌졸중 환자의 인지기 능과 일상생활활동 수행능력의 증진을 위한 방법으로 움직임의 정상 적 패턴을 반복적으로 학습시키는 것보다 더 높은 향상을 기대할 수 있다고 하였다. 이를 토대로 훈련 프로그램을 균형능력 향상을 위한 프로그램을 선정하였으며, 또한 학습 형태에 있어 프로그램을 진행 순서에 따라 학습 결과가 달라진다는 결과 ${ }^{8}$ 를 기반으로 구성하였다.

하지 근활성도에서 대퇴직근, 전경골근, 비복근에서 군간 비교에 서 RP군에서 더 유의한 향상이 있었다. Weiss 등근 뇌졸중 환자를 대상으로 12 주간 점진적 근력 강화 운동을 통해 근활성도를 통한 근 력에서 하지의 유의한 향상을 보고하였다. 대상자가 만성화된 뇌졸 중 환자들로 적극적인 훈련을 통해 근력에서 유의한 향상이 있었다 는 점은 본 연구에서도 만성화된 환자를 대상으로 시행해 근활성도 의 향상으로 나타난 결과와 유사하였다. $\mathrm{Ada}$ 등 18 은 근력증가의 효과 는 초기 뇌졸중 환자에게 적용한 경우에 근력 증가율이 컸고 만성환 자일수록 효과가 적다고 하였다. 그러나 본 연구 대상자들은 발병 20 개월 이상으로 만성화된 환자들이었으나 근활성도에서 향상을 확인 하였다. 이는 발병 후 평균 9년의 뇌졸중 환자를 대상으로 실시한 근 력강화프로그램에서 10 주 후 환측 하지 근력이 $25.1 \%$ 증가를 보고한 연구 결과 ${ }^{19}$ 를 지지한다. 또한 국내에서도 16 개월 이상 만성 편마비 환자를 대상으로 하지 근활성도에서 유의한 증가를 확인한 연구결
과와도 같았다. ${ }^{20}$ 이는 근력이 자연적으로 감소되는 현상에 대한 치 료 중재의 필요성을 다시 한번 확인하였다. ${ }^{21}$ 그리고 만성기에 접어든 편마비 환자라도 정형화된 프로그램이 아닌 예측할 수 없는 무선연 습 방법으로 시행했을 때 기능증진에 대한 학습 효과가 나타남을 확 인 할 수 있었다. 그리고 Diener 등2은 정적으로 서있는 동안 팔을 올 리는 동작과 같이 사지와 몸통의 움직임 때문에 생기는 무게중심의 불안정성에 대한 제어를 위해 전경골근(tibialis anterior), 넙다리 네갈 래근(quadriceps), 대퇴이두근(biceps femoris), 비복근(gastrocnemius) 과 같은 예비 근 활성이 필수적이다는 의견을 지지한다.

그리고 정적인 상태에서 체중 지지율과 균형유지에 관련된 압력중 심점(center of pressure) 이동거리는 서로 높은 상관관계가 있다는 선 행 연구 결과 23 를 바탕으로, 자세 안정을 위해서는 체중지지율이 서 로 대칭적인 상태가 중요하다고 판단하여 안정성 지수와 체중지지율 을 확인하였다. 연구 결과 안정성지수는 두 군 모두 유의한 향상이, 눈을 뜬 상태에서는 두 군 간 유의한 차이가 있었다. 체중 분포 지수 역시 두 군 모두 유의하게 향상되었고, 두 군 간 차이에서 RP군에서 유의한 향상이 있었다. 이는 Messier 등 24 과 Canbek 등 25 이 과제지향적 운동 프로그램을 통해 건강한 성인과 비교하여 균형과 운동성 측정 에서 균형능력과 자세 안정성(postural steadiness)이 향상된 결과와 같 았다. 또한 뇌졸중 환자를 대상으로 균형능력 향상을 보고한 연구결 과 $26-28$ 를 지지한다. 뇌졸중 환자는 마비측 하지의 근육이 비정상적으 로 동원되고 정적인 자세동요증가, 체중부하에 필요한 지구력 감소 로 인해 정적인 선 자세를 유지하기 어려워진다. ${ }^{23}$ 본 연구에서 사용 한 발디딤 전략과 체중지지 능력 향상을 목적으로 하는 과제지향훈 련을 규칙적인 순서가 아닌 무작위로 시행하여 대상자들이 예측할 수 없는 상태에 지속적으로 노출되어 대상자들이 평소에 익숙한 움 직임 패턴에서 벗어나 적응하기 위한 변화로 인한 결과로 생각된다.

이와 같은 결과를 종합해 보면 뇌졸중 환자의 균형능력의 향상을 위해서는 하지의 근활성도의 증가가 우선시 되야 하며, ${ }^{29}$ 운동단위 동 
원능력의 향상으로 인해 근활성도가 증가하고, 그 후 근 비대에 의해 근력증가 후 기능이 향상된다. 30,31 따라서 약화된 근육은 운동을 통 하여 근활성도를 증가시키고 균형 조절 능력 또한 증가시키는 데 도 움이 된다고 생각한다. 그리고 만성 편마비 환자의 경우 기존에 가지 고 있던 본인만의 패턴화된 움직임 틀을 수정 시킬 수 있는 중재가 필 요하다. 이를 위해 다양한 감각 자극과 기능적 활동을 효과적으로 제 시하고 일상생활 동작 수행 능력 향상에 도움을 줄 수 있는 과제들로 구성해야 하고, ${ }^{6}$ 임상에서는 변화 시킬 수 있는 운동 프로그램을 제시 해야 한다. 따라서 본 연구에서 적용한 무선 연습의 경우 구획연습에 비해 획득단계에서는 수행력이 낮으나 학습보존 단계에서는 수행력 이 더 높은 것으로 나타난 Lee와 Magill12 그리고 Dean등 32 의 연구 결 과를 지지하며 무선연습을 이용한 과제지향훈련이 만성 편마비 환자 의 근 활성과 균형능력 증진에 효과적인 중재 방법으로 생각된다.

본 연구의 제한점은 중재 전후의 효과만을 비교해 시간변화에 따 른 효과를 확인하지 못했으며, 추후 다른 신체 기능에 미치는 영향과 발병 경과기간에 따른 효과 차이를 알아보는 연구가 필요할 것으로 생각된다.

\section{REFERENCES}

1. Engberg W, Lind A, Linder A et al. Balance-related efficacy compared with balance function in patients with acute stroke. Physiother Theory Pract. 2007;24(2):105-11.

2. Karatas M, Çetin N, Bayramoglu M et al. Trunk muscle strength in relation to balance and functional disability in unihemispheric stroke patients. American journal of physical medicine \& rehabilitation. 2004; 83(2):81-7.

3. Andersson ÅG, Kamwendo K, Appelros P. Fear of falling in stroke patients: relationship with previous falls and functional characteristics. Int J Rehabil Res. 2008;31(3):261-4.

4. Tyson SF, Hanley M, Chillala J et al. Balance disability after stroke. Physical therapy. 2006;86(1):30-8.

5. Perry, Susan B. Stroke rehabilitation: guidelines for exercise and training to optimize motor skill. J Neurol Phys Ther. 2004;28(2):101.

6. Carr JH, Shepherd RB. Stroke rehabilitation: guidelines for exercise and training to optimize motor skill. Man Ther. 2003;8(4):261.

7. Shumway-Cook, AWoollacott MH. Motor control: translating research into clinical practice, Philadelphia, Lippincott Williams \& Wilkins, 2007:21-44.

8. Kim SJ. Motor learning \& control. Seoul, Deahanmidie, 2010:279-81.

9. Battig WF. The flexibility of human memory. Levels of processing and human memory, Lawrence Erlbaum Associates, Hillsdale, NJ. 1979:23-44.

10. Veyrac A, Allerborn M, Gros A et al. Memory of occasional events in rats: Individual episodic memory profiles, flexibility, and neural substrate. J Neurosci. 2015;35(19):7575-86.

11. Keetch KM, Lee TD. The effect of self-regulated and experimenter-imposed practice schedules on motor learning for tasks of varying difficul- ty. Res Q Exerc Sport. 2007;78(5):476-86.

12. Lee TD, Magill RA. The locus of contextual interference in motor-skill acquisition. Journal of Experimental Psychology: Learning, Memory, and Cognition. 1983;9(4):730.

13. Salbach NM, Mayo NE, Robichaud-Ekstrand S et al. The effect of a taskoriented walking intervention on improving balance self-efficacy poststroke: A Randomized, Controlled Trial. J Am Geriatr Soc. 2005;53(4): 576-82.

14. Basmajian JB, lumenstein R. Electrode placementin EMG biofeedback. Baltimore, Williams and Wilkins, 1980.

15. Laufer Y, Sivan D, Schwarzmann R. Standing balance and functional recovery of patient with right and left hemiparesis in the early stages of rehabilitation. Neurorehabil Neural Repair. 2003;17(3):207-13.

16. Blennerhassett JM, Jayalath VM. The four square step test is a feasible and valid clinical test of dynamic standing balance for use in ambulant people poststroke. Arch Phys Med Rehabil. 2008;89(11):2156-61.

17. Weiss A, Suzuki T, Bean J et al. High intensity strength training improves strength and functional performance after stroke. Am J Phys Med Rehabil. 2000;79(4):369-76.

18. Ada L, Dorsch S, Canning CG. Strengthening interventions increase strength and improve activity after stroke: a systematic review. Aust J Physiother. 2006;52(4):241-8.

19. Teixeira-Salmela LF, Olney SJ, Nadeau S et al. Muscle strengthening and physical conditioning to reduce impairment and disability in chronic stroke survivors. Arch Phys Med Rehabil. 1999;80(10):1211-18.

20. Yang DJ, Park SK, Kang JI et al. Effect of computerized feedback postural training on balance and muscle activity in stroke patients. J Kor Phys Ther. 2012;24(5):348-54.

21. Yang YR, Tsai MP, Chuang TY et al. Virtual reality-based training improves community ambulation in individuals with stroke: a randomized controlled trial. Gait posture. 2008;28(2):201-6.

22. Diener H-C, Dichgans J, Guschlbauer B et al. The coordination of posture and voluntary movement in patients with cerebellar dysfunction. Movement disorders. 1992;7(1):14-22.

23. Anker LC, Weerdesteyn V, van Nes IJ et al. The relation between postural stability and weight distribution in healthy subjects. Gait posture. 2008;27(3):471-7.

24. Messier S, Bourbonnais D, Desrosiers J et al. Dynamic analysis of trunk flexion after stroke. Arch Phys Med Rehabil. 2004;85(10):1619-24.

25. Canbek J, Fulk G, Nof L et al. Test-retest reliability and construct validity of the tinetti performance-oriented mobility assessment in people with stroke. J Neurol Phys Ther. 2013;37(1):14-9.

26. Lee JS, Nam Kw, Kim KY et al. Effect of weight bearing exercise on weight bearing and balance for patients with chronic stroke. J Kor Phys Ther. 2012;24(4):253-61.

27. Lee J, Lee KN. Effects of single-leg stance training of the involved leg on standing balance and mobility in patients with subacute hemiplegia. J Kor Phys Ther. 2011;23(4):1-6.

28. Shin WS, Song CH. Effects of virtual reality-based exercise on static balance and gait abilities in chronic stroke. J Kor Phys Ther. 2009;21(3):33-40.

29. LaRoche DP, Cremin KA, Greenleaf B et al. Rapid torque development in older female fallers and nonfallers: A comparison across lower-extremity muscles. J Electromyogr Kinesiol. 2010;20(3):482-8.

30. Häkkinen K, Pakarinen A, Kraemer WJ et al. Selective muscle hypertro- 
phy, changes in EMG and force, and serum hormones during strength training in older women. J Appl Physiol. 2001;91(2):569-80.

31. Mero A, Hulmi J, Salmijärvi H et al. Resistance training induced increase in muscle fiber size in young and older men. Eur J Appl Physiol. 2013;
113(3):641-50.

32. Dean CM, Richards CL, Malouin F. Task-related circuit training improves performance of locomotor tasks in chronic stroke: A randomized, controlled pilot trial. Arch Phys Med Rehabil. 2000;81(4):409-17. 